\title{
TUGAS PEDAGOGIS GEMBALA DALAM MENYIAPKAN WARGA GEREJA MENGHADAPI PERUBAHAN SOSIAL
}

\author{
Lenda Dabora J.F. Sagala \\ Sekolah Tinggi Teologi Simpson \\ Email: lendadsagala@gmail.com
}

\begin{abstract}
Social change is an inevitable conversation. Everyone needs to be prepared for social change. Likewise for church members, they need to be prepared for social change and there must be a pastoral pedagogical task in preparing church people for social change. The author conducts research by analyzing literature analysis to examine the issue. To prepare church members for social change, a pastor needs to conduct coaching that emphasizes Christian beliefs, so that these beliefs can be demonstrated in daily life. Then the second pedagogical task is the value of trust in church members. Human needs in the era of society 5.0 are strengthening the value of consideration and understanding in this context based on Christian principles. Gospel communication can fade because of the challenges of the times, but opposes social change in the era of the 5.0 shepherd community in support of providing guidance that leads to gospel communication. Church members need to be equipped to be able to communicate the gospel in the midst of a Christian perspective.
\end{abstract}

Keywords: Pastoral Pedagogical, Social Change, Church Citizens.

\begin{abstract}
Abstrak: Perubahan sosial adalah sebuah situasi yang tidak bisa dihindari. Setiap orang perlu dipersiapkan dalam menghadapi perubahan sosial. Demikian pula bagi warga gereja, mereka perlu dipersiapkan untuk menghadapi perubahan sosial dan tentunya ada tugas pedagogis gembala dalam menyiapkan warga gereja untuk meghadapi perubahan sosial. Penulis melakukan penelitian dengan pendekatan analisis literatur untuk mengkaji isu tersebut. Untuk mempersiapkan warga gereja menghadapi perubahan sosial seorang gembala perlu melakukan pembinaan yang menekankan pada penguatan keyakinan iman Kristen, sehingga keyakinan tersebut dapat didemonstrasikan dalam kehidupan sehari-hari. Kemudian tugas pedagogis kedua adalah memperkuat nilai kemanusiaan pada warga gereja. Kebutuhan manusia di era masyarakat 5.0 adalah penguatan nilai kemanusiaan dan tentunya dalam konteks ini berdasarkan prinsip-prinsip kekristenan. Komunikasi injil dapat memudar karena tantangan zaman, tetapi menghadapi perubahan sosial di era masyarakat 5.0 gembala berperan untuk memberikan pembinaan yang mengarah pada komunikasi Injil. Warga gereja perlu diperlengkapi untuk dapat mengomunikasikan Injil di tengah perubahan cara pandang tentang kekristenan.
\end{abstract}

Kata kunci: Pedagogis Gembala, Perubahan Sosial, Warga Gereja.

\section{PENDAHULUAN}

Perkembangan kehidupan manusia di abad 21 telah memasuki era revolusi industri 4.0 yang menghasilkan perubahan perilaku kehidupan manusia. Jika mencermati perubahan yang terjadi dalam kehidupan masyarakat, era revolusi industri 4.0 menghasilkan perubahan dari kehidupan masyarakat sosial dengan gotong royong, menjadi lebih individualistik (Ronda, 2019). Perkembangan kehidupan manusia di era revolusi industri 4.0 dan masyarakat 5.0 tampaknya menyentuh bebagai bidang seperti bidang ekonomi, pendidikan, kehidupan sosial dan berbagai bidang lainnya (Mumtaha \& Khoiri, 2019). Walau demiki- an, di era ini ada generasi emas yang juga butuh perhatian. Generasi emas ini menurut Prasetyo (2019) memiliki kreatifitas, inovasi, dan kemampuan adaptif yang tinggi, tetapi perlu didampingin agar berkarakter, memiliki interakasi sosial yang baik, dan kehidupan moral yang unggul.

Selain situasi di atas, Diana (2019b) mengungkapkan bahwa perkembangan teknologi di era revolusi industri 4.0 dapat berdampak pada pelaksanaan pendidikan Kristen. Salah satu yang menjadi tantangan adalah perubahan perilaku sosial yang cenderung menjadi lebih individualistik, oleh sebab itu tantangan tersebut perlu dijawab oleh pendidik Kris- 
ten baik dalam hal ini orang tua, guru, maupun gembala atau pendeta. Masalah yang berkaitan dengan interaksi sosial pada remaja Kristen adalah terjadinya kekerasan dalam pacaran. Masalah ini menurut Harmadi dan Diana (2020) adalah masalah individu yang kemudian menjadi masalah dalam interaksi sosial. Masalah interaksi sosial yang terjadi di era revolusi industri 4.0 adalah perubahan dari perilaku sosial interaksi langsung menjadi interaksi sosial enginering (Palinggi, Palelleng, \& Allolinggi, 2020).

Hasil dari perkembangan teknologi juga berdampak pada pola komunikasi antar manusia. Hal itu tidak lain sebagai dampak terhadap perubahan sosial. Diana (2019a) memandang pesatnya perkembangan teknologi memberi peluang pada komunikasi iman Kristen hanya tetap memperhatikan nilai-nilai kekristenan dan interaksi sosial. Diana, Katarina, Tamara, dan Priskila (2019, p. 91) berpendapat bahwa setiap manusia adalah makhluk sosial yang terus berinteraksi dengan manusian lainnya. Dalam hal ini orang Kristen perlu diperlengkapi untuk dapat memahami, menghargai, dan berinteraksi dengan sesama manusia. Dengan demikian, menurut Diana, orang Kristen dapat hidup berinteraksi sosial dengan baik.

Selain itu, sejarah panjang kehidupan masyarakat di Indonesia yang diwarnai berbagai konflik dengan nuansa SARA telah menjadi tantangan yang harus dijawab oleh gereja. Sagala (2016) mengungkapkan bahwa pemahaman yang kurang mendalam maupun perbedaan tafsir terhadap esensi ajaran agama dapat menjadi faktor penyebab terjadinya masalah kerukunan antar umat beragama. Konflik antara masyarakat awalnya bisa saja terkait dengan isu permasalahan sosial, ekonomi dan politik yang kemudian berkembang menjadi konflik antar umat beragama. Hal ini biasanya dipicu karena timbulnya rasa solidaritas antarkelompok yang berbeda pandangan keagamaan (Stefanus, 2009, p. 50).

Dalam rangka menyiapkan warga gereja menghadapi perubahan sosial, maka gereja perlu menjalankan fungsi pedagogisnya. Dalam konteks ini, tentunya untuk menjalankan fungsi tersebut gembala memegang peranan penting. Untuk membina jemaat agar mengalami pertumbuhan rohani tampak bahwa gembala memegang peranan penting. Penelitian yang dilakukan Widiyanto dan Susanto (2020), Berhitu (2014), dan penelitian Tafonao (2018) menunjukkan bahwa Gembala memiliki peranan penting untuk pembinaan rohani, mengembangkan pelayanan, memotivasi, dan mendorong warga gereja terlibat dalam pelayanan. Secara umum, Tanya (1999, p. 98) menjelaskan bahwa fungsi pedagogis gembala adalah sebagai pengajar secara umum di jemaat. Dalam tugas ini, gembala harus memastikan bahwa warga gereja adalah bagian dari komunitas belajar. Fungsi berikutnya adalah memberikan pengajaran melalui kelas katekisasi, memberi pengajaran teologi sebab warga gereja membutuhkan pengetahuan teologis, dan menyampaikan khotbah di mimbar gereja (Tanya, 1999, pp. 98-99). Penjelesanan Tanya tentang fungsi pedagogis gembala tampaknya masih bersifat umum. Menghadapi perubahan sosial masyarakat, fungsi pedagogis gembala tampaknya perlu dipertajam sehingga dapat memberikan kontribusi positif. Oleh sebab itu, rumusan masalah dalam kajian ini adalah apa peran pedagogis gembala dalam menyiapkan warga gereja menghadapi perubahan sosial? Tujuan penelitian ini adalah untuk memaparkan tentang peran pedagogis gembala dalam menyiapkan warga gereja menghadapi perubahan sosial.

\section{METODE}

Pendekatan penelitian yang digunakan dalam penelitian ini adalah penelitian kualitatif dengan analisis pustaka. Penelitian kualiatif dalam konteks penelitian keagamaan dapat berupa penelitian pustaka sehingga memberikan gagasan pemecahan masalah maupun gagasan teoritis praktis (Purwanto, 2016; Zaluchu, 2020). Gagasan awal penulis didasarkan pada tulisan Tanya (1999) tentang gereja dan pendidikan agama Kristen, kemudian tulisan Nainggolan (2009) berkaitan dengan pendidikan agama Kristen dalam konteks masyarakat majemuk, dan tulisan Stefanus (2009) yang juga bicara tentang kemajemukan. Karena gagasan awal yang bersumber dari tiga buku tersebut sudah agak lampau, maka penulis menganalisis beberapa artikel jurnal terbaru yang membahas tentang masyarakat majemuk, peran 
gembala, dan kehidupan sosial masyarakat. Kemudian menganalisis tulisan Schwab (2019), tulisan Haqqi dan Wijayati (2019) yang membahas tentang revolusi industri 4.0 dan society 5.0, dan tulisan Densmoor (2019) yang mencermati kehidupan spiritualitas dan religiousitas di era revolusi industri 4.0. Ketiga buku tersebut dipilih karena perubahan sosial yang terjadi saat ini tidak lepas dari era revolusi industri 4.0 dan society 5.0. Penulis juga menggunakan sumber-sumber lain yang dielaborasi menjadi sebuah gagasan. Selain itu, penulis juga mencermati konsep Alkitabiah yang berkaitan dengan isu ini sehingga gagasan yang dikemukakan memiliki landasan teologis Alkitabiah. Hasil analisis terhadap sumber-sumber tersebut kemudian penulis sajikan secara deskriptif.

\section{PEMBAHASAN}

\section{Penguatan Keyakinan Iman Kristen}

Pengaruh revolusi industri 4.0 terhadap individu manusia adalah mendorong manusia pada persoalan etis yang baru. Schwab (2019, pp. 127129) memandang bahwa perkembangan teknologi telah menyentuh aspek identitas diri, moral dan etis. Masalah lainnya adalah sentuhan sosial dapat berubah seiring dengan perubahan perilaku manusia. Schwab (2019, p. 131) menekankan bahwa kebutuhan manusia yang perlu dipecahkan adalah manusia memerlukan sentuhan manusiawi. Selain itu Haqqi dan Wijayati (2019, p. 35) mengungkapkan bahwa perkembangan teknologi di era revolusi industri 4.0 membawa perubahan sosial dimana terjadi ketimpangan antar masyarakat. Mencermati situasi tersebut, era masyarakat 5.0 mencoba menyeimbangkan antara perkembangan teknologi dengan aspek etis, manusiawi, spiritual, dan psikologis. Oleh sebab itu, dalam konteks keristenan perlu ada penguatan iman Kristen jemaat sehingga mampu menggunakan nilainilai kekristenan menghadapi perubahan zaman.

Tujuan pendidikan Kristen adalah membantu setiap orang percaya untuk mengalami pertobatan. Dalam iman Kristen, pertobatanlah yang memungkinkan tiap-tiap orang dapat melihat Kerajaan Allah dan mengalami kelahiran baru dalam Kristus (Sagala, 2016). Pendidikan Kristen juga bertujuan untuk orang percaya mengalami pertumbuhan rohani. Pertumbuhan rohani seseorang dapat terlihat dari dua aspek yaitu aspek vertikal dan horizontal. Aspek vertikal ialah diperbaharuinya hubungan seseorang dengan Allah yang dikokohkan melalui firman Allah dan doa. Sedangkan horizontal ditandai dengan praktik iman dalam hubungan dengan sesama. Pendidikan Kristen juga bertujuan untuk melaksanakan mandat pemuridan (Nainggolan, 2009; Sagala, 2016). Semua orang percaya adalah murid Kristus dan mempunyai hak untuk memperoleh pemeliharaaan dan pertumbuhan untuk menjadikannya murid-murid Kristus (Darmawan, 2017, 2019). Tujuan berikutnya dari pendidikan agama Kristen adalah pembentukkan karakter dan spiritual (Hartono, 2018; Sidjabat, 2019). Kehidupan rohani yang bertumbuh terjadi salah satunya karena adanya penanaman nilai-nilai rohani yang dihasilkan dari proses pembelajaran. Dalam hal ini, pendidikan Kristen memiliki tujuan agar orang percaya terus bertumbuh secara rohani (Nainggolan, 2009; Sagala, 2016).

Sesuai dengan tujuan pendidikan agama Kristen di atas, maka ada tugas pedagogis gembala dalam membantu jemaat menghadapi perubahan sosial yaitu penguatan keyakinan iman Kristen. Objantoro $(2014,2018)$ mengungkapkan bahwa pluralitas agama-agama selalu ada dalam dua sisi yaitu memberi nilai positif maupun tantangan. Bagi Objantoro (2018) pluralitas dan perubahan kehidupan sosial manusia memberi tantangan bagi keyakinan iman seseorang. Misalnya untuk dapat hidup di tengah masyarakat yang terus berubah dan memberi tantangan anggota jemaat akan mengubah pandangan hidup Kristennya atau keyakinan imannya agar dapat diterima dengan baik. Dalam hal ini, keyakinan iman Kristen harusnya tidak berubah melainkan diperkuat kemudian dinyatakan dalam kehidupan sosial. Dalam konteks ini, sejatinya hukum "Kasihilah Tuhan Allahmu.... di tunjukkan dalam kehidupan sosial. Nilai-nilai iman Kristen seperti kasih terhadap sesama manusia mewarnai kehidupan sosial yang terus berubah. Kemudian nilai-nilai iman Kristen 
dalam kalimat "kasihilah musuhmu" juga merupakan nilai penting dalam membangun kerukunan dan kehidupan sosial. Menurut Stefanus (2009) landasan teologisnya adalah manusia adalah ciptaan Allah yang diciptakan segambar dengan Penciptanya (Kej. 1). Memang dosa telah merusak gambar tersebut, tetapi karya Kristus telah membuat orang percaya mewarisi gambar Kristus yang penuh kasih, kemurahan, dan anugerah.

Dari uraian di atas maka dalam tugas penguatan keyakinan iman Kristen, gembala menyiapkan jemaat untuk mampu memahami keyakinan iman Kristenya sehingga warga gereja mampu mendemonstrasikannya dalam kehidupan sehari-hari. Penenakan pada pendalaman pemahaman teologi dan Alkitab sangat penting dalam pembentukan spiritualitas. Sebagai contoh pada masa reformasi gereja, tindakan praktis warga gereja mengalami masalah. Faktornya adalah pemahaman yang salah akan keyakinan iman Kristen. Itu sebabnya para reformator menekankan pada Sola Scriptura, sebab dengan kembali pada pemahan teologi alkitabiah pola piker dan tindakan praktis warga gereja pada masa itu dapat mengalami perubahan (Katarina \& Darmawan, 2019). Dalam upaya itu, tidak heran jika Luther terus mengajar warga gereja agar mengalami perubahan pola pikir yang kemudian didemonstrasikan dalam kehidupan sehari-hari.

\section{Penguatan Nilai Kemanusiaan}

Schwab (2019, p. 131) serta Haqqi dan Wijayati $(2019$, p. 36) melihat adanya perubahan nilai etis, moral, dan identitas yang kemudian berdampak pada perubahan nilai kemanusiaan. Persaingan kerja sebagai dampak dari otomasi juga mengubah perilaku sosial masyarakat. Manusia menjadi bersaing untuk memperoleh pekerjaan, bahkan ada kalanya mengambil jalan yang salah. Haqqi dan Wijayati (2019, p. 43) mencermati persaingan pekerjaan di kota berdampak pada perilaku masyarakat desa yang datang ke kota. Haqqi dan Wijayati melihat terjadinya prostitusi di perkotaan adalah akibat dari masalah ini. Masalah lain menurut Schwab (2019, p. 117) adalah terjadinya kesenjangan masyarakat atas, menengah dan bawah yang menjadi semakin jelas. Kondisi tersebut membutuhkan sentuhan manusiawi atau aspek humanism dan hal ini sejalan dengan harapan dari era masyarakat 5.0 (Fukuyama, 2018). Haqqi dan Wijayati (2019, p. 171) mengungkapkan bahwa di era masyarakat 5.0 diharapkan manusia mampu menghadirkan kerekatan antar manusia dan dapat saling menghormati. Manusia tidak hanya menjadi larut menjadi masyarakat yang konsumtif dengan produk perkembangan teknologi dan mengabaikan aspek kemanusiaan. Sama seperti pemerintah Jepang yang antisipatif terhadap kondisi ini, maka dalam konteks ini gereja melalui gembala juga perlu antisipatif. Oleh karena itu, perlu penanaman nilainilai humanism yang sejalan dengan perkembangan zaman tetapi tetap berlandaskan nilai-nilai kekristenan.

Humanism umumnya dipandang sebagai suatu nilai yang bertentangan dengan keyakinan Kristen. Tetapi Alkitab dalam Kejadian 2 menunjukkan bahwa Allah menciptakan manusia dengan nilai humanism atau kemanusiaan. Secara teologis menurut Stefanus (2009), orang percaya adalah umat Allah yang dipanggil keluar agar menjadi umat kesayangan-Nya. Dalam hal ini ada tanggungjawab untuk melakukan pelayanan kebersamaan manusia (Sagala, 2016). Secara teologis, Allah tidak menciptakan manusia atau masyarakat kelas dua, tetapi Ia menciptakan manusia serupa dengan gambar-Nya (Kej. 1:26-27). Walau manusia telah jatuh dalam dosa, Kejadian 3 menampilkan Allah yang datang memanusiakan manusia dan menolongnya. Oleh sebab itu, setiap orang percaya perlu diperlengkapi agar memiliki nilai kemanusiaan yang dilandaskan kasih Kristus.

Memasuki era masyarakat 5.0, telah terjadi perubahan tingkah laku mansyarakat yang terus mengikuti perkembangan teknologi sebagai hasil dari revolusi industri 4.0 dan berpusat pada kebutuhan manusia (Mumtaha \& Khoiri, 2019, p. 55). Lebih lanjut Muntaha dan Khoiri (Mumtaha \& Khoiri, 2019, p. 55) menjelaskan bahwa perilaku manusia di era masyarakat 5.0 diterjemahkan dengan kecerdasan buatan, lalu ditransformasikan dengan jutaan data 
di internet. Terjemahan data tersebut kemudian diharapkan menjadi sebuah kearifan baru sehingga dapat meningkatkan kemampuan manusia untuk membuka peluang kemanusiaan.

Sesuai dengan paparan di atas, maka tugas pedagogis gembala adalah melalukan penguatan nilai kemanusiaan pada warga gereja. Penguatan nilai kemanusiaan sangat berkaitan dengan ciri pendidikan Kristen yang berorientasi pada terjadinya pembaharuan, penghayatan, pembentukan sikap serta pembentukan jadi diri manusia (Nainggolan, 2009, p. 79). Implikasi dari ciri pendidikan Kristen adalah ada tugas pedagogis gembala untuk menguatkan nilai kemanusiaan pada setiap anggota jemaat. Pendidikan agama Kristen berorientasi kepada manusia yaitu menyangkut pembaharuannya, penghayatannya, pembentukkan sikap dan perilakunya serta pembentukkan jati dirinya.

Tugas pedagogis gembala dalam hal ini adalah mewartakan nilai-nilai kemanusiaan baik melalui khotbah, kelompok pendalaman Alkitab, maupun pelayanan personal. Gembala perlu merancang sebuah kurikulum khotbah maupun pendalaman Alkitab yang berorientasi pada nilai kemanusiaan. Kurikulum tersebut tentunya berfokus pada sosok Yesus yang menjadi model dalam kehidupan sosial.

Yesus telah memberi contoh bagaimana memanusiakan manusia. Beberapa contoh yang Yesus lakukan adalah 1) Yesus menolong perempuan sundal yang ingin dirajam karena dosanya (Yoh. 8:111). Dalam peristiwa tersebut, Yesus justru berbicara bahwa siapa di antara mereka yang tidak berbuat dosa maka ia boleh lebih dahulu merajam perempuan tersebut. Peristiwa ini menunjukkan bahwa semua manusia berdosa, tetapi Yesus menaruh nilai kemanusiaan dalam peristiwa itu; 2) Kisah lainnya adalah kisah tentang perempuan Samaria yang berjumpa dengan Yesus di sumur Yakub (Yoh. 4:1-42). Perjumpaan itu dianggap sebagai sebuah peristiwa yang tidak umum pada waktu itu. Tetapi dalam peristiwa itu, Yesus justru menunjukkan nilai kemanusiaan pada perempuan itu. Yesus justru menyadarkan perempuan tersebut akan kehidupannya yang tidak benar. Yesus tidak menolak atau menjauhi pe- rempuan itu, tetapi Yesus hadir membawa pembaharuan hidup bagi perempuan tersebut; 3) Perjumpaan Zakheus dan Yesus juga merupakan bukti bahwa Yesus menekankan nilai kemanusiaan (Luk. 19:1-10). Yesus memutuskan untuk masuk rumah Zakheus dan makan sehidangan dengannya. Kehadiran Yesus di rumah Zakheus yang tidak disukai orang tampak membawa pembaharuan pada diri Zakheus; 4) Perjumpaan Yesus dengan Matius, seorang pemungut cukai juga menunjukkan bahwa ada nilai kemanusiaan dalam diri Yesus (Mat. 9:9-13; Mrk. 2:13-17; Luk. 5:27-32). Kehadiran Yesus di hadapan Zakheus tampaknya mengubah pandangan Matius akan dirinya dan akhirnya mengikut Yesus; 5) Belas kasihan Yesus pada manusia juga tampak ketika Ia menyembuhkan orang-orang sakit (Mat. 8:14-17; 14:34-36; Mrk. 6:53-56; 7:31-37; Luk. 4:40; 10:9; Yoh. 5:3; 6:2). Yesus menjamah orang lumpuh, orang buta, dan sakit kusta. Dalam setiap peristiwa di mana Yesus menyembuhkan orang-orang sakit, justru Yesus tampak menaruh perhatian pada orangorang tersebut. Umumnya orang-orang tersebut dianggap kelas rendah, tetapi Yesus memandang bahwa mereka adalah orang-orang yang butuh pertolongan dan perlu dibangun kembali kehidupannya; 6) Peristiwa kerasukan di Gerasa juga menampilkan Yesus menekankan nilai kemanusiaan (Mat 8:28-34; Mark 5:1-20; Luk 8:26-39). Dalam peristiwa tersebut, Yesus justru menekankan pada pentingnya keselamatan orang yang kerasukan tersebut. Yesus memanusiakan orang kerasukan tersebut dengan meminta para murid memberinya pakaian. Umumnya orang yang dianggap gila seperti dalam peristiwa di Gerasa dikuncilkan oleh masyarakat, dianggap najis, dan hina. Tindakan Yesus dalam hal ini justru berbeda apa yang umumnya orang lakukan, yang tampil adalah rasa kasih dan kemanusiaan Yesus.

Teladan Yesus seperti dalam penjelasan di atas dapat menjadi acuan dalam pembinaan warga gereja untuk penanaman nilai-nilai kemanusiaan. Itu sebabnya kurikulum pembinaan gereja perlu diarahkan kepada penanaman nilai kemanusiaan yang mungkin menjadi luntur di tengah perubahan sosial masyarakat. Gembala dalam hal ini berperan mem- 
prakarsai dan mengimplementasikannya dalam pembinaan warga gereja.

\section{Pembinaan Untuk Komunikasi Injil}

Era revolusi industri 4.0 dan masyarakat 5.0 adalah era dengan komunikasi yang cepat. Perkembangan teknologi sebagai hasil dari revolusi industri 4.0 menjadikan perubahan dalam komunikasi. Peluang komunikasi antar manusia menjadi semakin mudah dan cepat (Haqqi \& Wijayati, 2019; Schwab, 2019). Sampe (2019, p. 72) menjelaskan bahwa komunikasi menjadi tercipta menjadi semakin cepat, sehingga era ini mengubah cara manusia dalam berkomunikasi. Oleh sebab itu, kekristenan perlu mentrasformasi tugas pelayanan sehingga dapat memperlengkapi warga gereja menghadapi perubahan. Sampe (2019) juga menjelaskan bahwa peran pendidikan Kristen dalam hal ini adalah membimbing generasi Kristen agar mereka memiliki indentitas diri dan bertumbuh secara iman. Menurut penulis, jika hal itu dilakukan maka warga gereja dapat dipersiapkan untuk komunikasi Injil yang lebih efektif.

Karena perubabahan pola komunikasi telah terjadi maka pola komunikasi Injil juga perlu mengalami perubahan. Diana (2019a) menjelaskan bahwa perubahan yang terjadi di era revolusi industri menuntut adanya perubahan pola komunikasi Injil. Perubahan ini dibutuhkan agar terjadi efektifitas komunikasi Injil. Sebab menurut Stefanus (2009) keselamatan harus diberitakan bagi seluruh manusia termasuk dalam era ini. Dengan demikian, interaksi sosial yang terbentuk di era masyarakat 5.0 dapat menjadi wadah untuk mewartakan kasih Allah bagi seluruh umat manusia. Injil yang dimaksudkan dalam konteks ini adalah anugerah Allah dalam Kristus Yesus bagi seluruh ciptaan.

Beberapa masalah komunikasi Injil di era revolusi industri 4.0 adalah perubahan pola pikir tentang spiritualitas (Densmoor, 2019). Densmoor (2019) mengamati generasi millennial yang mendominasi era revolusi industri 4.0 dan era masyarakat 5.0 mengalami perubahan konsep tentang spiritualitas, termasuk tentang gereja. Secara teologis, dosa adalah salah satu faktor masalah dalam kehidupan sosial dan berdampak dalam berbagai aspek kehidupan manusia, termasuk juga terkait dengan kehidupan sosial.

Itu sebabnya penyiapan warga gereja menghadapi situasi tersebut menjadi penting. Gembala memiliki peran penting dalam menyiapkan warga gereja melakukan komunikasi Injil di era ini. Dampak dari Covid 19 pada awal hingga menjelang tahun 2020 tampaknya juga berdampak pada pola komunikasi Injil. Itu sebabnya pembinaan warga gereja perlu dipersiapkan menghadapi situasi ini. Penelitian Octavianus (2018) menunjukkan telah terjadinya perubahan pola komunikasi Injil, tetapi peluang yang disediakan di era revolusi industri 4.0 memberi kesempatan kemudahan komunikasi Injil. Aplikasi yesHeis menjadi salah satu bentuk komunikasi Injil yang relevan dengan perkembangan zaman. Tetapi hal ini dapat berhasil jika ada peran serta gembala melakukan pembinaan warga gereja untuk memanfaatkan situasi ini.

\section{KESIMPULAN}

Dari analisis beberapa sumber di atas ada beberapa tugas pedagogis gembala dalam mempersiapkan warga gereja menghadapi perubahan sosial. Peran pertama adalah melakukan pembinaan yang menekankan pada penguatan keyakinan iman Kristen, sehingga keyakinan tersebut dapat didemonstrasikan dalam kehidupan sehari-hari. Perubahan sosial, terutama jika terjadi perubahan pada nilai-nilai kemajemukan dan multikultural, termasuk perubahan padangan pluralisme dapat menyebabkan degradasi keyakinan iman Kristen. Oleh sebab itu, perlu penguatan nilai iman Kristen sejalan dengan tantangan zaman.

Kemudian tugas pedagogis kedua adalah memperkuat nilai kemanusiaan pada warga gereja. Aspek kemanusiaan dapat menjadi masalah di era 4.0 itu sebabnya kebutuhan manusia di era masyarakat 5.0 adalah penguatan nilai kemanusiaan. Oleh sebab itu, gembala berperan untuk menyiapkan warga gereja memiliki nilai kemanusiaan yang berdasarkan prinsip-prinsip kekristenan. 
Komunikasi injil dapat memudar karena tantangan zaman. Perubahan pola pikir manusia tentang spiritualitas menuntut tindakan nyata gereja. Oleh sebab itu menghadapi perubahan sosial di era masyarakat 5.0 gembala berperan untuk memberikan pembinaan yang mengarah pada komunikasi Injil.

\section{DAFTAR RUJUKAN}

Berhitu, R. J. (2014). Peran Gembala Jemaat Terhadap Pengembangan Pelayanan Holistik Di Gereja Kemah Injil Indonesia Jemaat Yegar Sahaduta Jayapura. Jurnal Jaffray, 12(2), 273-290. https://doi.org/10.25278/jj71.v12i2.19

Darmawan, I. P. A. (2017). Murid yang Memuridkan. In Melaksanakan Amanat Agung Di Abad 21. Ungaran: Sekolah Tinggi Teologi Simpson.

Darmawan, I. P. A. (2019). Jadikanlah Murid: Tugas Pemuridan Gereja Menurut Matius 28:1820. Evangelikal: Jurnal Teologi Injili dan Pembinaan Warga Jemaat, 3(2), 144-153.

Densmoor, M. (2019). Injil Bagi Free Thinker. Surabaya: Momentum.

Diana, R. (2019a). Peran Komunikator Kristen Dalam Strategi Pekabaran Injil Di Era Revolusi Industri 4.0. Integritas: Jurnal Teologi, 1(1), 66-73.

Diana, R. (2019b). Prinsip Teologi Kristen Pendidikan Orang tua terhadap Anak di Era Revolusi Industri 4.0. BIA': Jurnal Teologi Dan Pendidikan Kristen Kontekstual, 2(1), 27-39. https://doi.org/10.34307/b.v2i1.79

Diana, R., Katarina, K., Tamara, Y., \& Priskila, K. (2019). Prinsip Hidup Kristen di Tengah Masyarakat yang Majemuk. Veritas Lux Mea (Jurnal Teologi Dan Pendidikan Kristen), 1(2), 90-99.

Fukuyama, M. (2018). Society 5.0: Aiming for a New Human-Centered Society. Japan SPOTLIGHT, (2), 47-50.

Haqqi, H., \& Wijayati, H. (2019). Revolusi Industri 4.0 di tengah Society 5.0. Yogyakarta: Quadrant.
Warga gereja perlu diperlengkapi untuk dapat mengomunikasikan Injil di tengah perubahan cara pandang tentang kekristenan. Selain itu peluang yang disediakan di era revolusi industri 4.0 dan masyarakat 5.0 terbuka luas bagi komunikasi Injil secara luas.

Harmadi, M., \& Diana, R. (2020). Tinjauan PsikoTeologi Terhadap Fenomena Kekerasan Dalam Pacaran Pada Remaja. Evangelikal: Jurnal Teologi Injili dan Pembinaan Warga Jemaat, 4(1), 92-102.

Hartono, H. (2018). Membentuk Karakter Kristen Pada Anak Keluarga Kristen. Kurios, 2(1), 62-69. https://doi.org/10.30995/kur.v2i1.22

Katarina, K., \& Darmawan, I. P. A. (2019). Implikasi Alkitab dalam Formasi Rohani pada Era Reformasi Gereja. EPIGRAPHE: Jurnal Teologi Dan Pelayanan Kristiani, 3 (2), 81-93. https://doi.org/10.33991/epigraphe.v3i2.85

Mumtaha, H. A., \& Khoiri, H. A. (2019). Analisis Dampak Perkembangan Revolusi Industri 4.0 dan Society 5.0 Pada Perilaku Masyarakat Ekonomi (E-Commerce). JURNAL PILAR TEKNOLOGI: Jurnal Ilmiah Ilmu Ilmu Teknik, 4(2), 55-60. https://doi.org/10.33319/piltek.v4i2.39

Nainggolan, J. M. (2009). PAK Dalam Masyarakat Majemuk Pedoman Bagi Guru Agama Kristen Dalam Mengajar. Bandung: Bina Media Informasi.

Objantoro, E. (2014). Pluralisme Agama-Agama: Tentangan Bagi Teologi Kristen. Jurnal Simpson: Jurnal Teologi dan Pendidikan Agama Kristen, 1(1), 61-80.

Objantoro, E. (2018). Religious Pluralism And Christian Responses. Evangelikal: Jurnal Teologi Injili Dan Pembinaan Warga Jemaat, 2(1), 123-133.

Octavianus, S. (2018). Analisis Penggunaan Aplikasi yesHeis Dalam Penginjilan Pribadi. Evangelikal: Jurnal Teologi Injili dan 
Pembinaan Warga Jemaat, 2(1). Retrieved from

https://journal.sttsimpson.ac.id/index.php/EJ TI/article/view/92

Palinggi, S., Palelleng, S., \& Allolinggi, L. R. (2020). Peningkatan Rasio Kejahatan Cyber Dengan Pola Interaksi Sosio Engineering Pada Periode Akhir Era Society 4.0 Di Indonesia. Jurnal Ilmiah Dinamika Sosial, 4(1), 145-163.

Prasetyo, P. E. (2019). Membangun Karakter Budaya Entrepreneurship Profesional: Kunci Sukses SDM Menuju Generasi Emas dan Daya Saing. Prosiding Seminar Nasional Sains \& Entrepreneurship IV, 1, 611-618. Retrieved from http://103.98.176.39/index.php/snse/article/v iew/242

Purwanto, H. (2016). Manfaat Penelitian Untuk Perkembangan Gereja. Prosiding Seminar Nasional Pendidikan Agama Kristen STT Simpson Tahun 2016 Tema: Strategi Pembinaan Jemaat Untuk Meningkatkan Kehidupan Jemaat. Presented at the Seminar Nasional Pendidikan Agama Kristen \& call for papers, Ungaran.

Ronda, D. (2019). Kepemimpinan Kristen Di Era Disrupsi Teknologi. Evangelikal: Jurnal Teologi Injili dan Pembinaan Warga Jemaat, 3(1), 1-8.

Sagala, L. D. J. F. (2016). Peran Pendidikan Kristen Dalam Menghadapi Perubahan Sosial. Jurnal Simpson: Jurnal Teologi Dan Pendidikan Agama Kristen, 1(1), 47-54.
Sampe, N. (2019). Meretas Kecakapan Komunikasi Interpersonal Keluarga Kristen Memasuki Era 4.0. BIA': Jurnal Teologi Dan Pendidikan Kristen Kontekstual, 2(1), 72 82. https://doi.org/10.34307/b.v2i1.84

Schwab, K. (2019). Revolusi Industri Keempat. Jakarta: Gramedia Pustaka Utama.

Sidjabat, B. S. (2019). Penguatan Guru PAK Untuk Pendidikan Karakter: Melihat Kontribusi Seri Selamat. Evangelikal: Jurnal Teologi Injili dan Pembinaan Warga Jemaat, 3(1), $30-48$.

Stefanus, D. (2009). Pendidikan Agama Kristen Kemajemukan. Bandung: Bina Media Informasi.

Tafonao, T. (2018). Peran Gembala Sidang Dalam Mengajar Dan Memotivasi Untuk Melayani Terhadap Pertumbuhan Rohani Pemuda. Evangelikal: Jurnal Teologi Injili dan Pembinaan Warga Jemaat, 2(1), 36-49.

Tanya, E. (1999). Gereja dan Pendidikan Agama Kristen, Mencermati Peranan Pedagogis Gereja. Cipanas: Sekolah Tinggi Teologi Cipanas.

Widiyanto, M. A., \& Susanto, S. (2020). Pengaruh Pelayanan Kunjungan Pastoral Terhadap Pertumbuhan Rohani Jemaat. Evangelikal: Jurnal Teologi Injili Dan Pembinaan Warga Jemaat, 4(1), 39-46.

Zaluchu, S. E. (2020). Strategi Penelitian Kualitatif dan Kuantitatif Di Dalam Penelitian Agama. Evangelikal: Jurnal Teologi Injili dan Pembinaan Warga Jemaat, 4(1), 28-38. 